\section{Análise espacial de áreas com restrição legal de uso do solo em
projeto de assentamento no sudeste paraense \\ Análise espacial de áreas com restrição legal de uso do solo em
projeto de assentamento no sudeste paraense}

Castro*

Orlando dos Santos Watrin **

Resumo: A implantação de projetos de assentamentos na Amazônia é uma atividade que gera grandes impactos ambientais quando não vem acompanhada de um planejamento adequado. Este trabalho visou mapear o uso e cobertura da terra na área do projeto de assentamento 26 de Março, Marabá, Sudeste do Pará, para avaliar a situação das áreas com restrições legais de uso da terra, através de produtos e técnicas de sensoriamento remoto e de geoprocessamento. Os resultados mostraram que a paisagem da área de estudo é dominada por pastagens cultivadas e vegetação secundária, sendo as áreas de floresta bem mais modestas. Também observou-se que uma parcela considerável das Áreas de Preservação Permanente está em desacordo com a legislação ambiental. Em relação à Reserva Legal, apesar da mesma ainda não ter sido averbada, neste trabalho foi feita uma proposição baseada em nível de lote.

\section{Spatial analysis of jurisdictional land use areas on the rural settlement project in southeastern of Pará State, Brazilian Amazon.}

\begin{abstract}
The implementation of rural settlement projects in the Amazon can generate large impacts on the environment when are not associated with adequate planning. This study aimed at mapping land use and land cover in the area of the settlement project 26 de Março, in Marabá, Southeast of Pará State, Brazil, in order to assess the status of jurisdictional land use. We relied on products and techniques of remote sensing and GIS.The results showed that the study area landscape is dominated by pastures and secondary vegetation, with few original remaining forest fragments as forest areas are much more modest. We also observed that a considerable portion of the Permanent Preservation Areas does not comply with the Brazilian laws related to protection of riparian zones. In relation to the Legal Reserve, even though the same have not yet been deployed, this study a proposition was made based on level allotment.
\end{abstract}

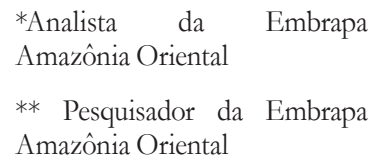

Palavras-chave:

Projeto de Assentamento Rural; Código Florestal; Ordenamento Territorial

Key-Words:

Rural Settlement Project; Brazilian Forestry Code; Territory Order 


\section{Introdução}

Os projetos de assentamentos (PAs) constituem uma estratégia praticada pelo INCRA como tentativa de que trabalhadores rurais atinjam seu desenvolvimento econômico, promovendo também o ordenamento fundiário (ALBUQUERQUE et al., 2004). No Sudeste Paraense, segundo Homma et al. (2001), "a ação do INCRA tem sido muito mais em regularizar fatos consumados das invasões", pois muitas das áreas ocupadas já possuíam um passivo ambiental elevado quando sofreram o processo de desapropriação. Naturalmente, os colonos que foram acomodados nestas áreas herdaram o passivo ambiental correspondente.

Sem recursos suficientes para promover a reconstrução da mata nativa, além da falta de planejamento e orientação técnica para o parcelamento e a instalação da área Reserva Legal (RL) e da área destinada ao uso, os colonos acabam por manter e até aumentar este passivo. Watrin et al. (2005) verificaram em alguns projetos de assentamentos no Sudeste Paraense, que a redução das áreas de floresta primária está associada aos períodos de ampliação das atividades agropecuárias, cuja intensidade é variável com o local e o período de tempo analisado. Isto tem como consequência direta, prejuízos ambientais, como a formação de áreas degradadas e retração dos remanescentes florestais, que acabam se refletindo no dia-a-dia do produtor.

A preservação da mata existente em uma área é importante não só para a manutenção da vegetação per si, mas também de outros elementos naturais que compõem o ecossistema local. Para garantir a preservação da vegetação, foi instituído o novo Código Florestal brasileiro, Lei 4471/65, de 15 de setembro de 1965 (Brasil, 2011), que regula o uso sobre as florestas e demais formações vegetais, possuindo grande impacto sobre as propriedades rurais, principalmente, devido aos artigos que tratam das Áreas de Preservação Permanente (APPs) e da RL. Segundo Oliveira et al. (2008), tal impacto deriva do fato que a Lei Ambiental não exime as propriedades rurais do cumprimento dos requisitos legais previstos em lei, no que se tange a alocação das APPs e averbação da RL.

Fiscalizar o cumprimento da legislação em locais de atividades que estão ligadas ao meio ambiente na Amazônia é uma tarefa difícil, dada as especificidades da região e a falta de material, principalmente humano, para os órgãos responsáveis realizarem tais fiscalizações. As ferramentas de geotecnologias têm ajudado os órgãos governamentais e outras instituições a terem um panorama da realidade ambiental na Amazônia.

As geotecnologias permitem a observação e o monitoramento de grandes áreas de maneira sistemática, integrando diversas informações em uma base de dados. As geotecnologias têm se apresentado como importantes ferramentas na detecção de danos ambientais, pois possibilitam análises complexas através da integração de informações diversas de diferentes fontes e de maneira integrada, permitindo uma ampla visão da dinâmica dos elementos que constituem determinada área. Watrin et al. (2009) afirmam que os estudos ambientais podem auxiliar no entendimento dos processos da dinâmica de uso da terra. Assim, este entendimento é sobremaneira importante para o desenvolvimento equilibrado das atividades nos projetos de assentamentos rurais, aliado à preservação da natureza. Soares e Espíndola (2008) atentam para a importância do emprego das geotecnologias no planejamento dos assentamentos rurais, a fim de conseguir estabelecer um ambiente sustentável.

Considerando essas premissas, este trabalho visa, a partir do uso integrado de produtos

Geografia Ensino \& Pesquisa, v. 17, n. 2 p. 157-166, maio/ago. 2013

Análise espacial de áreas com restrição legal de uso do solo em projeto de assentamento no Sudeste Paraense e técnicas de sensoriamento remoto e geoprocessamento, mapear o uso e cobertura da terra na área do PA 26 de março, localizado no município de Marabá, Pará, com o intuito de avaliar a situação das APPs e da RL, oferecendo, assim, elementos ao processo de repensar as estratégias para o uso e ocupação sustentável deste território.

\section{Área de Estudo}


A área de estudo corresponde ao PA 26 de março, criado em 19/12/2008 a partir da área da antiga fazenda Cabaceiras, que está localizado no município de Marabá, mesorregião do Sudeste Paraense (Figura 1). Contando com uma área de 11.919,36 ha, o projeto de assentamento pode ser acessado através da BR-155, a qual corta a área na direção norte-sul, sendo sua rede de drenagem subordinada, em grade parte, ao rio Sororó que constitui o limite a oeste do mesmo. Esta área apresenta seis núcleos de moradia e duas sedes, além de 207 lotes familiares. A disposição espacial dos lotes no PA 26 de março segue o modelo conhecido como "raio-de-sol" (Figura 2) que se caracteriza por apresentar áreas comuns onde são construídas as casas dos assentados com lotes próximos às mesmas (BERTOLINI; CARNEIRO, 2007).

Figura 1 - Localização da área de estudo.

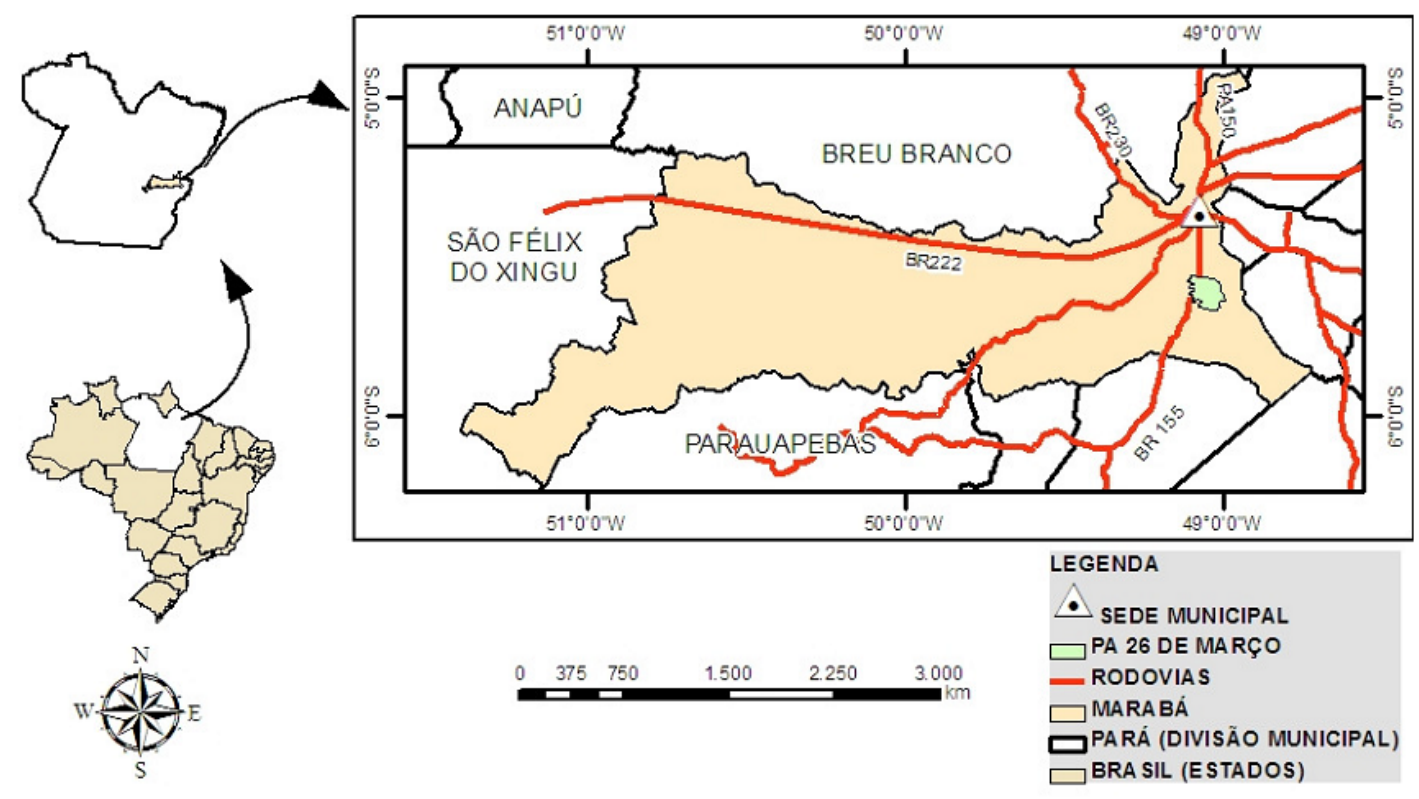

Figura 2 - Distribuição espacial dos lotes do PA 26 de março, Marabá-PA.

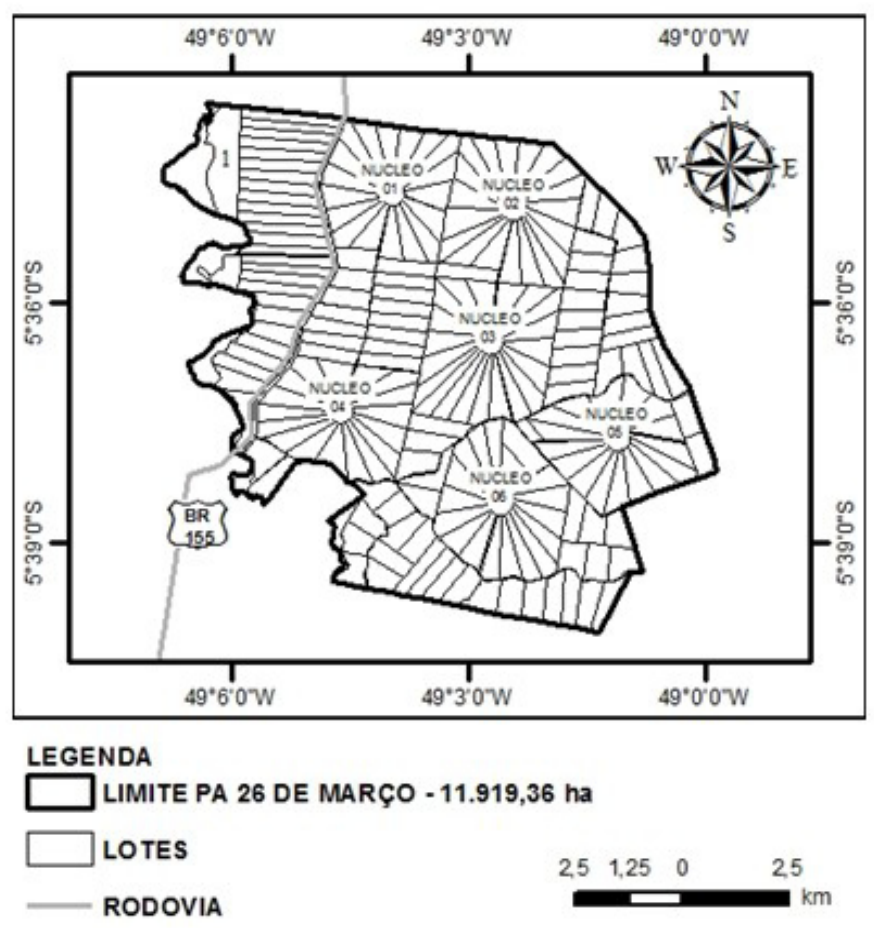

Geografia Ensino \& Pesquisa, v. 17, n. 2 p. $157-166$, maio/ago. 2013 


\section{Material e Métodos}

Neste trabalho utilizou-se produtos de sensoriamento remoto e as técnicas de processamento digital de imagens e geoprocessamento para criação da base de dados geográficos, adotando-se a escala de 1:25.000 e o sistema de coordenadas geográficas referenciadas ao datum SIRGAS 2000. O tratamento e análise do conjunto de dados georreferenciados da área de estudo foram conduzidas nos programas Spring 5.1.7 e, ArcGIS 10. Para mapeamento do uso e cobertura da terra, utilizou-se a imagem do sensor HRG do satélite SPOT-5 na órbita-ponto 703/361 de 27/06/2009, com resolução espacial de 2,5 $\mathrm{m}$. Visando o adensamento dos canais de drenagem compatível com a escala adotada, foi utilizada a imagem do Projeto Topodata de identificação 5 S495 (INPE/DPI, 2011), que é um produto originado da interpolação por krigagem de dados SRTM ${ }^{1}$, resultando numa resolução espacial de $30 \mathrm{~m}$ (VALERIANO, 2004). Por fim, os dados vetoriais utilizados foram o limite do projeto de assentamento, fornecido pelo INCRA - SR 27, e o da proposta de divisão dos lotes, fornecido pela Empresa de Assistência Técnica e Extensão Rural do Estado do Pará (EMATER-PARÁ), seção Marabá.

Inicialmente, preparou-se a base de dados com os vetores do limite do projeto de assentamento e a dos lotes, além de uma máscara retangular que serviu como polígono envolvente a todos os dados de interesse, para facilitar o processamento dos mesmos. Posteriormente, realizou-se a classificação supervisionada por regiões, tomando-se por base a legenda temática e a metodologia descritas em detalhe por Watrin et al. (2009), realizando, primeiramente, o processo de segmentação da imagem HRG/SPOT, adotando como limiares de similaridade e área os valores 10 e 80, respectivamente. O limiar de área adotado corresponde a 2 ha, sendo determinado a partir de identificação em campo como sendo o tamanho médio das áreas cultivadas. Após a segmentação, procedeu-se à classificação por regiões propriamente dita, a partir do algoritmo Bhattacharya, que por ser um método supervisionado, necessita de um conhecimento prévio das feições ocorrentes na área de estudo, o que foi suprido a partir de trabalhos de campo intensivos quando foram feitas diversas observações para constatação da paisagem in loco.

Desta forma, foram definidas nove classes temáticas: Floresta, Capoeira Alta, Capoeira Baixa, Pasto Limpo, Pasto Sujo, Solo Agrícola sob Preparo, Solo Exposto, Campo Higrófilo e Corpo d'água. Para facilitar a visualização das classes e se ter uma noção melhor da preservação e da ação antrópica na área do projeto de assentamento, foi feito um agrupamento das classes temáticas iniciais em duas novas classes temáticas. As classes Floresta, Capoeira Alta e Campo Higrófilo foram agrupadas numa nova classe denominada Áreas Preservadas. Já as classes Capoeira Baixa, Pasto Limpo, Pasto Sujo, Solo Agrícola sob Preparo e Solo Exposto foram agrupadas na classe denominada Áreas Antropizadas.

A imagem classificada foi convertida para o formato shapefile e aplicando ferramentas do software ArcGis 10, foi possível quantificar os valores de área para cada classe determinada. Posteriormente, foram cruzados os limites dos lotes do projeto de assentamento com este produto temático, obtendo-se desta maneira a ocorrência das classes em cada lote. A partir do resultado deste cruzamento, foi possível determinar o valor em porcentagem de área preservada e de área antropizada que cada lote possui, o que serviu de embasamento para a proposição das áreas de RL.

Considerando a necessidade de ser feita a delimitação das APPs para a área de estudo,

Geografia Ensino \& Pesquisa, v. 17, n. 2 p. $157-166$, maio/ago. 2013

Análise espacial de áreas com restrição legal de uso do solo em projeto de assentamento no Sudeste Paraense foram gerados os canais de drenagem em uma escala maior do que 1:100.000. Para isto, utilizou-se a imagem Topodata (resolução espacial de $30 \mathrm{~m}$ ), sendo a ela aplicada a ferramenta Arc Hydro Tools do ArcGis 10, para geração automática de canais de drenagem, com base no valor de cada pixel da imagem. Entretanto, como o produto desta operação foi gerado na escala de 1:150.000, fez-se necessário adequá-lo à escala utilizada na base de dados geográficos constituída através da edição manual, a partir da interpretação visual da imagem HRG/SPOT. 
Assim, foi possível visualizar diversos canais de drenagem antes não mapeados, gerando um produto final mais refinado na escala de 1:25.000.

Com os canais de drenagem gerados, foi possível determinar as APPs para o PA 26 de março, de acordo com o Código Florestal de 1965, baseando-se na largura média dos canais fluviais. Como a maioria dos canais existentes no PA 26 de março possui largura média de até $10 \mathrm{~m}$, a largura de APP considerada para cada margem foi de $30 \mathrm{~m}$. Somente no Rio Sororó, cuja largura média é de $49 \mathrm{~m}$, houve a necessidade de ajustar o valor da largura mínima da APP para $100 \mathrm{~m}$. Após determinadas as APPs, estas foram cruzadas com o resultado da classificação de uso e cobertura da terra, obtendo-se, assim, o percentual das APPs que estão preservadas e que estão antropizadas.

Para a proposição da área de RL, foi levada em consideração a configuração espacial da área, o que envolve a disposição dos lotes, a forma como a área foi ocupada e o uso e cobertura da terra. Constatou-se que toda a área do projeto de assentamento foi desmembrada em lotes familiares e núcleos de moradia, não tendo sido, a priori, disponibilizada uma área comum para a constituição da RL comunitária. Assim, como forma de viabilizar a RL dentro do projeto de assentamento sem alterar drasticamente o arranjo espacial dos lotes já configurado e a dinâmica produtiva que já está instalada no espaço pelos assentados, considerou-se uma proposição baseada em Reservas Legais individuais para cada lote de maneira que o arranjo das mesmas seja disposto para formar corredores contínuos de vegetação árborea (corredores biológicos), inclusive com a inserção de um fragmento florestal significativo, possibilitando à área, como um todo, maior resistência e coesão a eventos devastadores, como o fogo, e ao mesmo tempo favoreça o desenvolvimento natural da fauna e da flora.

\section{Resultados e Discussão}

Com base nos resultados obtidos, gerou-se um gráfico (Figura 3) onde pode ser observada a distribuição em área das classes de uso e cobertura da terra determinadas para a área de estudo. Verificou-se que a paisagem do PA 26 de março é marcada pela presença de pastagens cultivadas, além das áreas revestidas com vegetação secundária, que contribuem respectivamente com $41,38 \%$ e $29,73 \%$ do total da área.

Figura 3 - Quantificação das áreas das classes de uso e cobertura do solo no PA 26 de março, Marabá - PA.
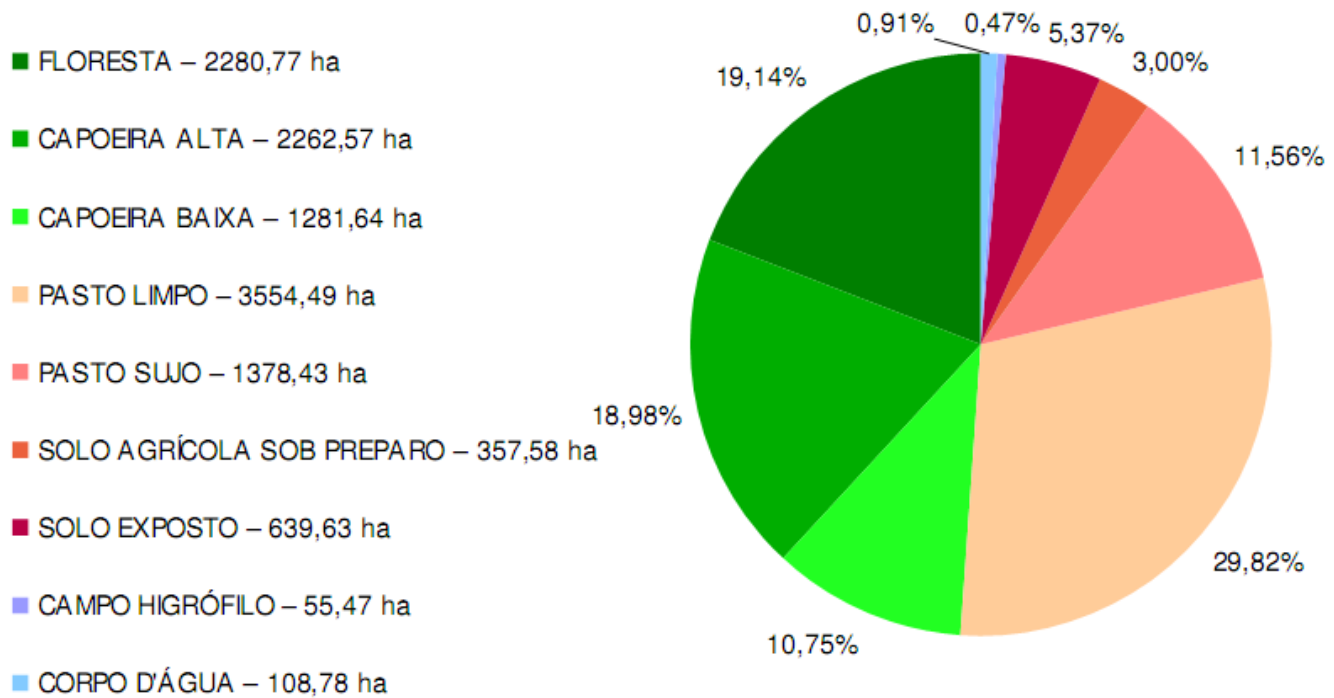

Geografia Ensino \& Pesquisa, v. 17, n. 2 p. $157-166$, maio/ago. 2013 
No contexto das classes de uso da terra, Mertens et al. (2002) destacam que em muitas áreas na Amazônia a feição de maior evidência em termos de área corresponde às pastagens em seus diferentes estados. Adicionalmente, Watrin et al. (2005) observaram que as pastagens representam o padrão dominante do uso da terra em projetos de assentamentos no Sudeste Paraense, com incrementos significativos em área nos períodos analisados. As demais classes ligadas ao sistema produtivo (Solo Agrícola sob Preparo e Solo Exposto) contribuem juntas com apenas $8,37 \%$ do total.

Apesar das formações florestais presentes no projeto de assentamento encontrarem-se parcialmente antropizadas, ainda constituem remanescente valioso do ecossistema original, ocupando 19,14\% da área total do projeto de assentamento. Por sua vez, as áreas de campo higrófilo, contribuindo com uma parcela muito modesta ( $0,47 \%$ do total), são encontradas na forma de pequenas manchas, na várzea do Rio Sororó.

A Figura 4 apresenta a distribuição espacial da classificação final. A distribuição espacial das unidades de paisagem encontradas no PA 26 de Março apresenta uma concentração de floresta e capoeira alta mais significativa na porção central do projeto de assentamento, porção essa que possui relevo mais movimentado, conforme constatado por levantamento em campo. As áreas de pasto, solo agrícola e solo exposto estão bastante dispersas ao longo da área do projeto de assentamento, implicando em uma relativa fragmentação da paisagem pelos arranjos produtivos locais. Vale ressaltar que principalmente próximo às vias de acesso, as pastagens são o elemento dominante da paisagem, contrastando com os remanescentes da vegetação ripária que acompanham as margens dos canais de drenagem que cruzam os pastos.

Figura 4 - Uso e cobertura da terra no PA 26 de março, Marabá-PA.

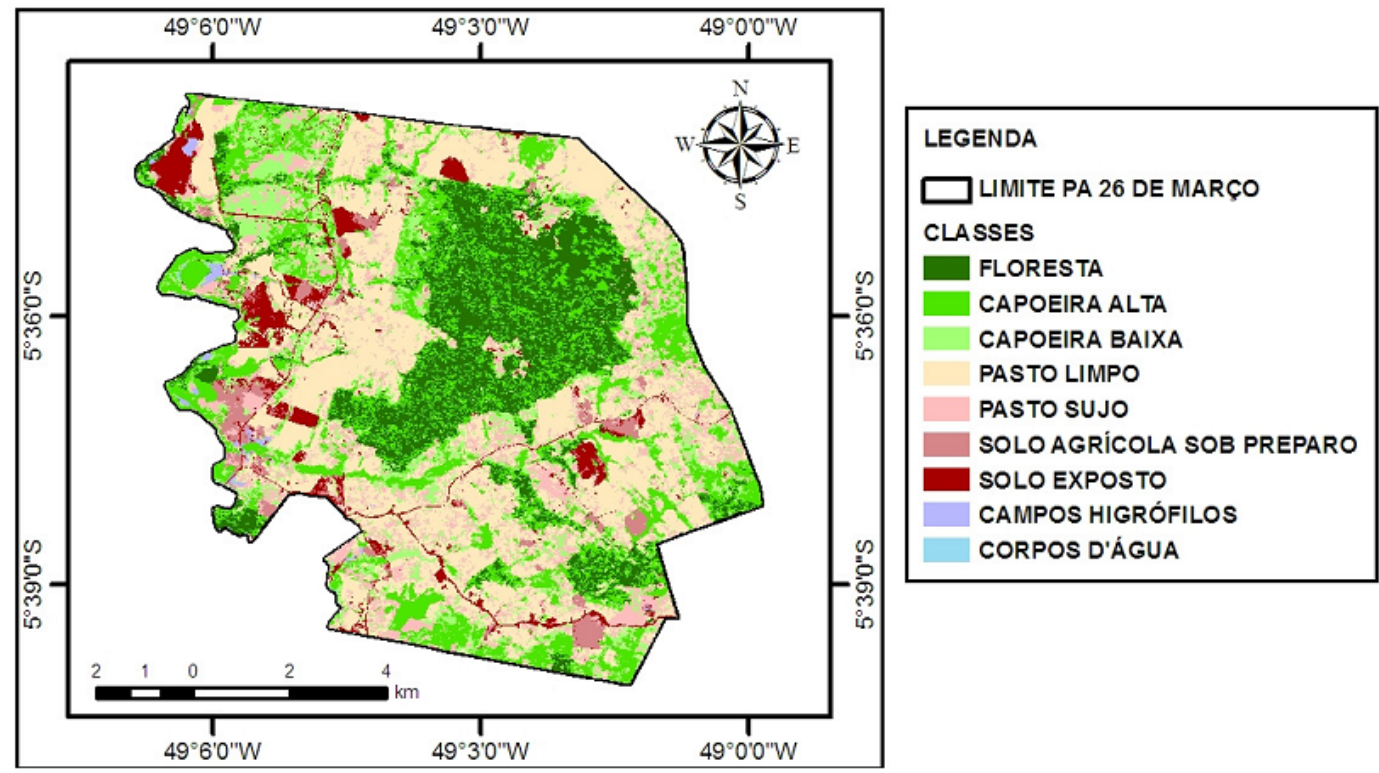

O resultado do agrupamento das classes temáticas iniciais nas classes Áreas Preservadas e Áreas Antropizadas é apresentado na Figura 5.

As áreas ligadas ao sistema produtivo somadas têm percentual de área de $60,5 \%$, bem

Geografia Ensino \& Pesquisa, v. 17, n. 2 p. $157-166$, maio/ago. 2013

Análise espacial de áreas com restrição legal de uso do solo em projeto de assentamento no Sudeste Paraense maior do que as áreas destinadas à preservação ambiental, que somaram 38,59\%. A classe Corpo d'água não foi inserida em nenhum agrupamento por não ser considerada para cômputo de área de RL.

Por outro lado, a configuração espacial dos lotes no projeto de assentamento promove a formação de um mosaico de unidades de paisagem bem distintas dentro do mesmo espaço. Isto ocorre em função da divisão dos lotes onde cada assentado busca satisfazer suas necessidades 
de acordo com suas possibilidades técnicas e financeiras. Desta forma, alguns procuram se sustentar através de variadas práticas agrícolas e até mesmo da extração madeireira (Watrin et al. 2005). Assim, a paisagem reflete as ações de cada assentado e sua família no processo de transformação do espaço.

Figura 05 - Áreas preservadas e áreas antropizadas no PA 26 de março, Marabá - PA.

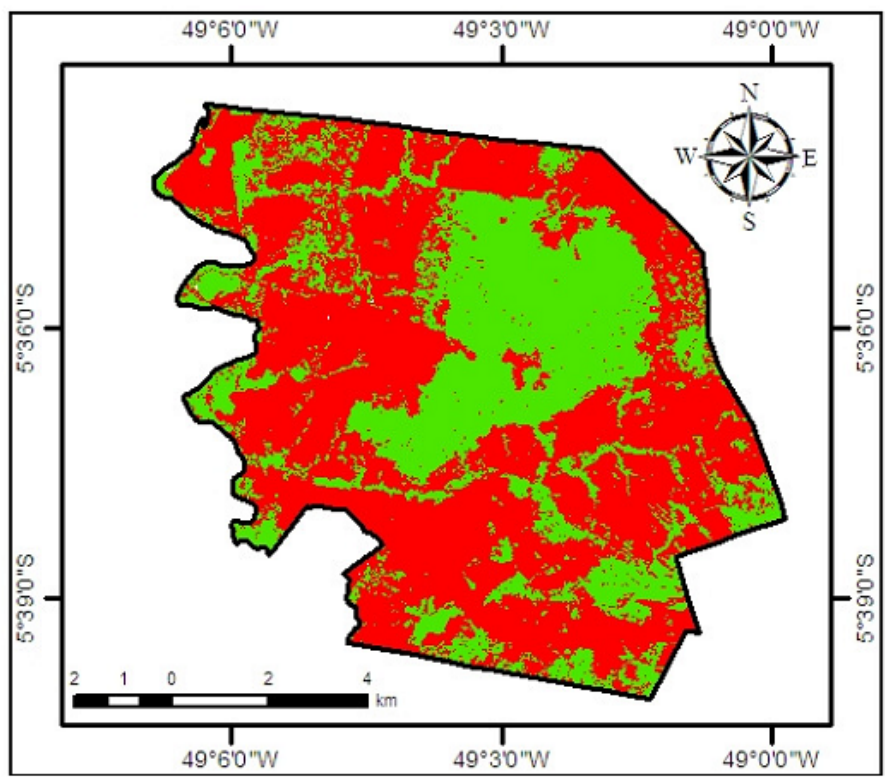

\section{LEGENDA \\ $\square$ LIMITE PA 26 DE MARÇO \\ ÁREA ANTROPIZADA - 60,5\% \\ ÁREA PRESERVADA - $\mathbf{3 8 , 5 9 \%}$}

Na Figura 6 é possível visualizar a disposição espacial dos lotes juntamente com as áreas preservadas e as áreas antropizadas no PA 26 de março. Pôde-se notar que nos núcleos de moradia, há o desmatamento quase total das áreas a eles destinadas. Ainda assim, nos núcleos de moradia 2, 3 e 4, foi observado que em alguns lotes próximos aos mesmos há significativa preservação das áreas florestais, principalmente na porção que fica mais distante dos respectivos núcleos.

Figura 6 - Lotes com classes do PA 26 de março.
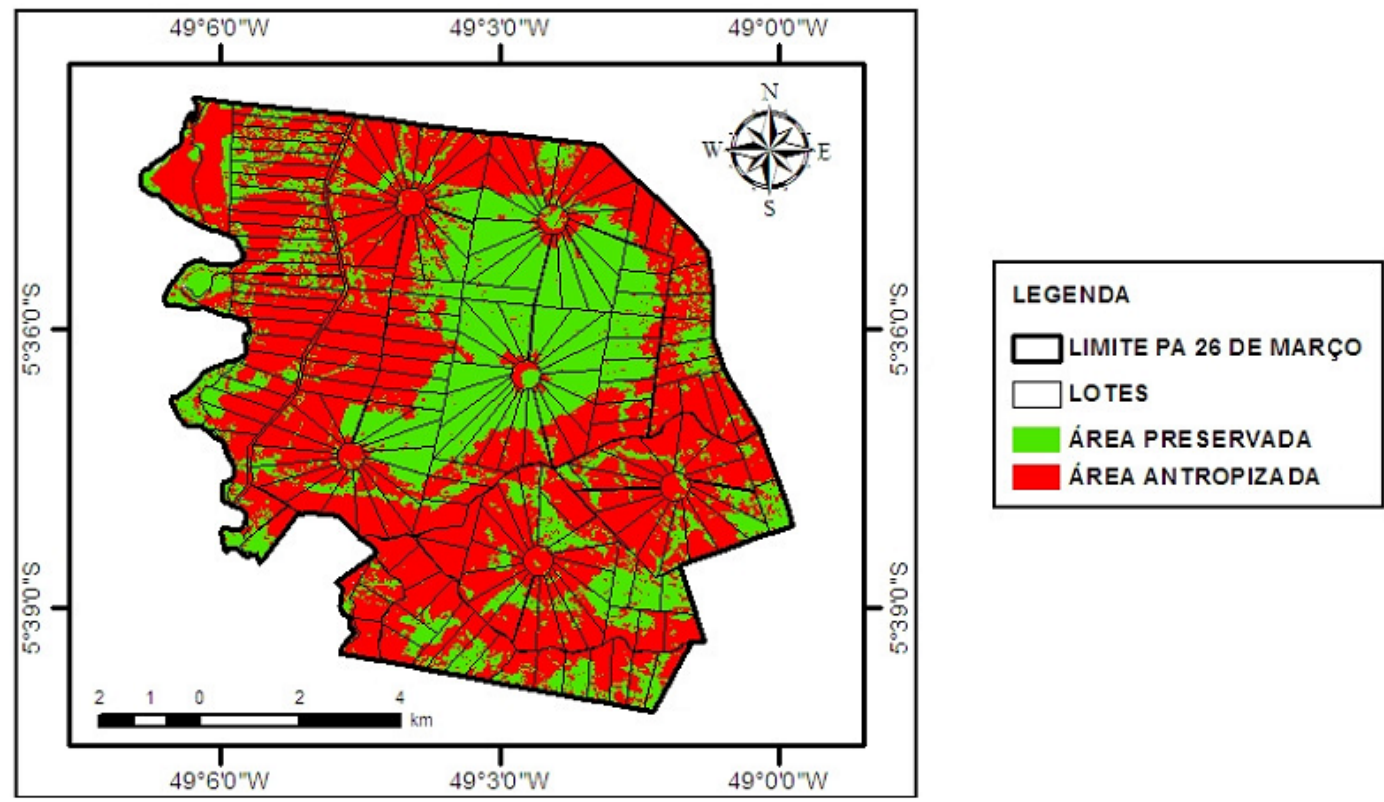

Também foi possível notar que há lotes que apresentam nenhuma ou quase nenhuma

Geografia Ensino \& Pesquisa, v. 17, n. 2 p. 157-166, maio/ago. 2013 
área preservada, principalmente nas proximidades da rodovia BR-155. Já na parte central do projeto de assentamento, onde há uma grande área de floresta, dos lotes que lá se localizam, alguns chegam a apresentar até $100 \%$ de área preservada. Isso é importante para o planejamento da área para ações futuras, inclusive de possíveis compensações de outras áreas. Some-se a isto o fato de que tais áreas ainda apresentam remanescentes vegetais e animais de suma importância para possíveis reconstituições da flora nas áreas degradadas.

Em relação aos canais de drenagem gerados, foi possível determinar que há 146.645,80 $\mathrm{m}$ de canais de drenagem na área de estudo. De acordo com a legislação vigente, as APPs perfazem um total de 848,4433 ha, sendo que 509,9648 ha ou $60,11 \%$ são de áreas preservadas, e os 338,4785 ha ou 39,89\% restantes, são de áreas antropizadas, passíveis de recuperação (Figura 7).

Figura 7 - Integridade das APPs no PA 26 de março, Marabá, PA.

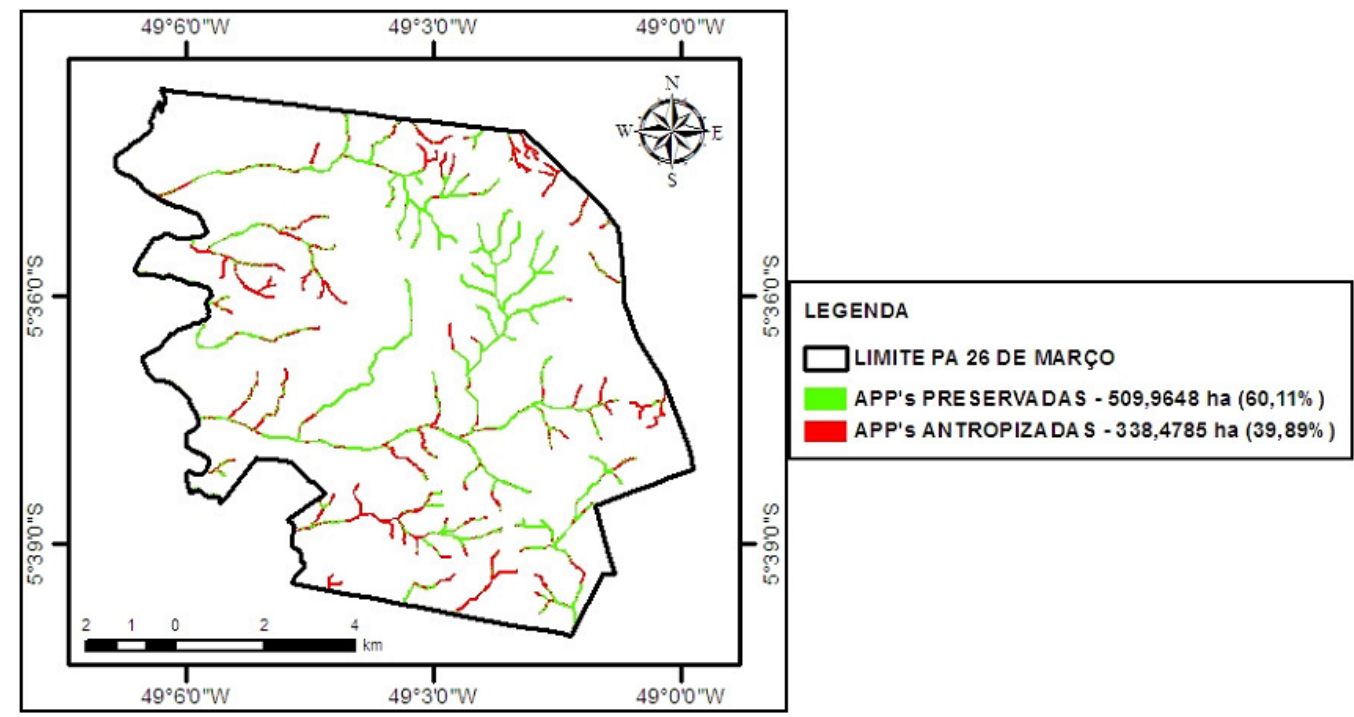

Boa parte das APPs preservadas encontra-se dentro do fragmento florestal no centro do projeto de assentamento. Também vale destacar que parte das APPs que não estão preservadas encontra-se em trechos de canais intermitentes. Dessa forma, é premente proceder a revegetação destas áreas, preferencialmente com espécies pertencentes ao ecossistema original e/ou de interesse imediato dos assentados, de modo a atender o estabelecido na legislação em vigor.

Por fim, a proposição de áreas para RL utilizou a proporção de $80 \%$ de área preservada para 20\% de área de uso alternativo do solo dentro dos lotes, o que corresponde respectivamente a 9.535,49 ha e 2.383,87 ha, de forma que os usos e as áreas onde já estão instalados pudessem, tanto quanto possível, permanecer inalterados. Assim, na construção da RL por lote (Figura 8), buscou uma configuração espacial que conciliasse ao máximo a distribuição das manchas de tipologia vegetal existentes, com as áreas já destinadas ao sistema produtivo.

Entende-se que essa proposta de construção da RL constitui apenas uma tentativa de

Geografia Ensino \& Pesquisa, v. 17, n. 2 p. $157-166$, maio/ago. 2013

Análise espacial de áreas com restrição legal de uso do solo em projeto de assentamento no Sudeste Paraense se chegar a um produto que concilie questões ambientais com os anseios dos assentados. Configurações espaciais da RL que estimulem a fragmentação de áreas florestais devem ser evitadas, sendo os futuros impactos aos mesmos minimizados quando o sistema produtivo for implantado considerando preceitos de zoneamentos agroecológicos legitimados pelos próprios assentados. 
Figura 8 - Proposta para criação de Reserva Legal por lote no PA 26 de março, Marabá, PA.

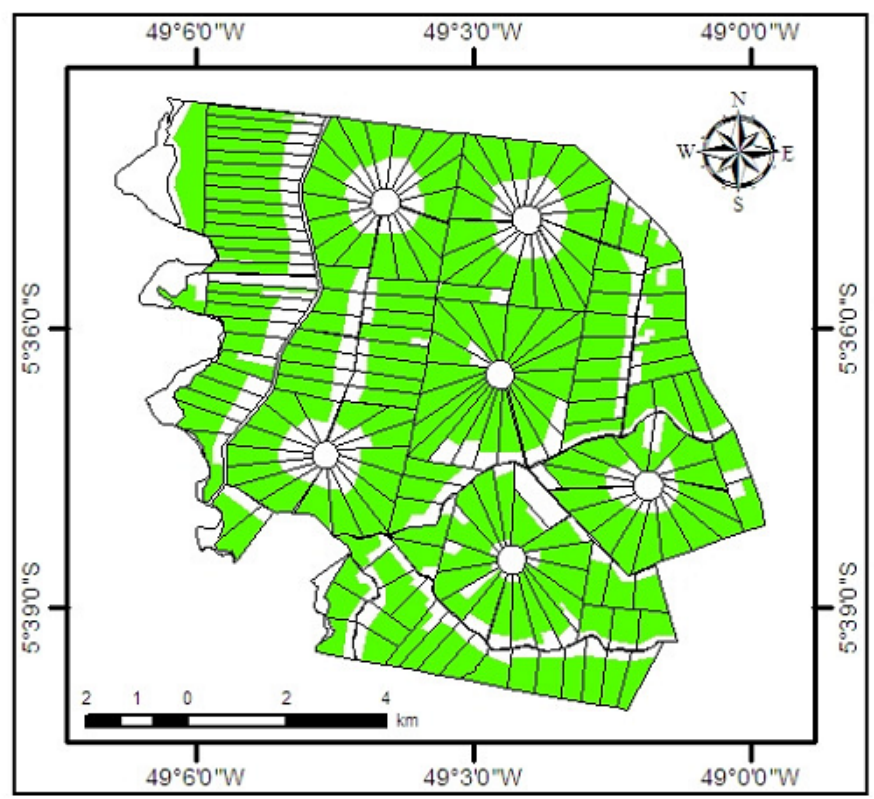

\section{LEGENDA \\ LIMITE PA 26 DE MARÇO \\ LOTES \\ ÁREA PARA RESERVA LEGAL}

\section{Conclusões}

Com base nos resultados obtidos, pode-se observar que a paisagem do PA 26 de março é dominada por pastagens cultivadas sendo as demais classes ligadas ao sistema produtivo de pouca expressão. Por outro lado, as áreas de floresta ocupam uma porção modesta quando comparadas às de vegetação secundária.

Observou-se também que a área de estudo possui um grande passivo ambiental, já que mais da metade da mesma está sob intervenção antrópica de modo que a própria dinâmica de ocupação da área provavelmente inviabilizou a criação da área de RL anteriormente. Além disto, a integridade das Áreas de Preservação Permanente está parcialmente em desacordo com a legislação ambiental. Por tudo isso, é imprescindível que as lideranças do assentamento comunguem esforços no sentido de resolver esta situação, através de projetos e ações de recomposição das APPs e de averbação da RL.

Adicionalmente, é necessário que outros estudos sejam realizados, como os relativos ao solo e à aptidão agrícola das terras, com fins de planejamento de ações que visem à produção a partir de cultivo, pecuária ou mesmo extrativismo. A busca de parceiros neste processo facilitaria os arranjos necessários para viabilização da recuperação e adequação de áreas com a legislação vigente. Com tais medidas busca-se assim, compatibilizar questões de interesse díspares, como aquelas de cunho ambiental e as ligadas ao sistema produtivo, dentro de um contexto que reflita as realidades física e humana locais.

\section{Agradecimentos}

Os autores agradecem à equipe do Projeto Nativas da Embrapa Amazônia Oriental, em especial aos colegas Maria do Socorro G. Ferreira, Delman de Almeida Gonçalves e Fabrício Nascimento Ferreira pela oportunidade de realizar o presente trabalho. Tais agradecimentos são extensivos a Antonio Guilherme Soares Campos, pelo apoio no desenvolvimento técnico deste trabalho, a Luiz Paulo Corrêa dos Reis que gentilmente realizou a revisão gramatical deste artigo e a Pedro Gherard pela elaboração do abstract.

Geografia Ensino \& Pesquisa, v. 17, n.2 p. 157-166, maio/ago. 2013

Castro, A. R. C.; Watrin, O. S 


\section{Referências}

ALBUQUERQUE, F. J. B. de; COELHO, J. A. P. de M.; VASCONCELOS, T. C. As políticas públicas e os projetos de assentamento. Estudos de Psicologia. João Pessoa: 2004. p. 81 - 88.

BERTOLINI, V.A.; CARNEIRO, F.F.; Considerações sobre o planejamento espacial e a organização da moradia dos assentamentos de reforma agrária no DF e entorno. Libertas, v. Edição especial, 2007. Disponível em http://www.ufjf.br/revistalibertas/files/2011/02/artigo11_6.pdf. Acessado em $25 / 05 / 2011$

BRASIL. Casa Civil. Lei n 4.771/1965. Institui o novo Código Florestal. Disponível em http:// www.mma.gov.br/port/conama/legiabre.cfm?codlegi=311. Acessado em 19/04/2011.

HOMMA, A.K.O.; CARVALHO, R.A.; SAMPAIO, S.M.N.; SILVA, B.N.R.; SILVA, L.G.T.; OLIVEIRA, M.C.C. A instabilidade dos projetos de assentamento como indutora de desmatamentos no Sudeste Paraense. Disponível em: http://www.ecoeco.org.br/conteudo/publicacoes/encontros/iv_en/ mesa5/3.pdf. Acessado em: 23/11/2011.

INSTITUTO NACIONAL DE PESQUISAS ESPACIAIS/ DIVISÃO DE PROCESSAMENTO DE IMAGENS (INPE/DPI). Topodata: banco de dados morfométricos do Brasil. Disponível em http://www.dsr.inpe.br/topodata/index.php. Acessado em 03/2011.

MERTENS, B.; POCCARD-CHAPUIS, R.; PIKETTY, M.G. et al. Crossing spatial analyses and livestock economics to understand deforestation process in the Brazilian Amazonia: the case of São Félix do Xingu in south Pará. Agricultural Economics. v. 27, p. 269-294.

OLIVEIRA, Y.M.M.; ROSOT, M.A.D.; GARRASTAZÚ, M.C. Roteiro metodológico para planos de manejo em fazendas experimentais. Colombo, PR. Embrapa Florestas, dez. 2008. 9 p. (Embrapa Florestas. Comunicado Técnico, 205). ISSN 1517-5030.

SOARES, J.L.N.; ESPÍNDOLA, C.R. Geotecnologias no planejamento de assentamentos rurais. NERA, v. 11, n. 12, p. 108 - 116, set. 2008. Disponível em: http://www2.fct.unesp.br/nera/revistas/12/13_ soares_e_espindola_12.pdf. Acessado em 24/11/2011.

VALERIANO, M.M. Modelo digital de elevação com dados SRTM disponíveis para a América do Sul. São José dos Campos, SP: INPE: Coordenação de Ensino, Documentação e Programas Especiais (INPE-10550-RPQ/756). 72p., 2004.

WATRIN, O.S.; GERHARD, P.; MACIEL, M.N.M. Dinâmica do uso da terra e configuração da paisagem em antigas áreas de colonização de base econômica familiar, no nordeste do Estado do Pará. Geografia, v. 34, n. 3, p. 455-472, set.-dez., 2009.

WATRIN, O.S.; CRUZ, C.B.M.; SHIMABUKURO, Y.E. Análise evolutiva da cobertura vegetal e do uso da terra em projetos de assentamentos na fronteira agrícola amazônica, utilizando geotecnologias. Geografia, v. 30, n. 1, p. 59-76. jan-abr. 2005.

\section{Correspondência:}

\section{Allison Reynaldo Castro}

E-mail: allicastro@hotmail.com

Geografia Ensino \& Pesquisa, v. 17, n. 2 p. $157-166$, maio/ago. 2013

Análise espacial de áreas com restrição legal de uso do solo em projeto de assentamento no Sudeste Paraense
Recebido em 09 de novembro de 2012.

Revisado pelo autor em 03 março de 2013.

Aceito para publicação em 14 de abril de 2013. 